\title{
Synthesis of Micro- and Nanoparticles of Metal Oxides and Their Application for Reinforcement of Al-Based Alloys
}

\author{
S. Vorozhtsov, ${ }^{1}$ I. Zhukov, ${ }^{1}$ A. Vorozhtsov, ${ }^{1}$ A. Zhukov, ${ }^{1}$ D. Eskin, ${ }^{1,2}$ and A. Kvetinskaya ${ }^{1}$ \\ ${ }^{1}$ National Research Tomsk State University, Tomsk 634050, Russia \\ ${ }^{2}$ Brunel Centre for Advanced Solidification Technology, Brunel University, Kingston Lane, Uxbridge UB8 3PH, UK \\ Correspondence should be addressed to S. Vorozhtsov; vorn1985@gmail.com
}

Received 20 June 2014; Revised 4 September 2014; Accepted 10 September 2014

Academic Editor: Wim Sillekens

Copyright (c) 2015 S. Vorozhtsov et al. This is an open access article distributed under the Creative Commons Attribution License, which permits unrestricted use, distribution, and reproduction in any medium, provided the original work is properly cited.

\begin{abstract}
This paper presents a comparative analysis of morphology, chemical and phase compositions, and particle size distribution of nanopowders produced by electric explosion of wire (EEW) and plasma-chemical methods. The possibility of introduction of $\mathrm{Al}_{2} \mathrm{O}_{3}$ particles into $\mathrm{Al}$ alloy by means of a special master alloy and with ultrasonic processing is shown. The improvement of tensile properties of an Al-based composite material reinforced with $0.1 \mathrm{wt} \%$ of $\mathrm{EEW} \mathrm{Al}_{2} \mathrm{O}_{3}$ is demonstrated.
\end{abstract}

\section{Introduction}

Development of lightweight materials with a wide range of improved properties makes it possible to use new high strength parts and structures and significantly improve energy efficiency and product design (vehicle weight reduction, reduction of material consumption for production, etc.) $[1,2]$. Composite materials based on Al light alloys represent a metal matrix with specified distribution of reinforcing elements (particles, fibers, etc.). In this case individual properties of components of such composites are used efficiently (to the maximum extent). One of the possible and promising methods of improving the physical and mechanical properties (Young's modulus, ultimate tensile strength, yield strength, hardness, durability, and specific electrical and thermal properties) of Al-based metal-matrix composites (MMC) is the introduction of micro- and nanoparticles of oxides (nitrides, borides, and carbides) into the melt with subsequent solidification [2-6]. Methods of production of nonmetallic micro- and nanoparticles can significantly affect morphology and physical properties of nanopowders. Thus, the particle structure, phase composition, and morphology are to be studied carefully in order to assure the properties of alloys produced using these particles.
It is known that direct introduction of nonmetallic particles (especially nanosized ones) into liquid metal is hindered by the fact that they are prone to agglomeration caused by their low wettability by liquid metal. This problem can be solved in two ways, by using special concentrated master alloys as well as by using external fields acting on liquid metals with particles which leads to deagglomeration of nanoparticles and their homogeneous distribution in the melt volume and eventually ingot structure. Ultrasonic treatment is one of the efficient ways of melt treatment leading to alloy grain size reduction and homogeneous distribution of reinforcing particles in its structure $[7,8]$. The use of master alloys produced by means of shockwave (SW) compaction method is of current interest in alloy casting $[9,10]$. This method makes it possible to obtain dense compacted material (with the density close to theoretical value) with simultaneous introduction of required quantities of reinforcing and modifying particles into the mixture. The concentrated master alloy can then be used for introduction of a measured amount of reinforcement into the melt, also using ultrasonic processing.

The main objective of this work is to synthesize oxide nanoparticle, that is, $\mathrm{Al}_{2} \mathrm{O}_{3}, \mathrm{ZrO}_{2}-\mathrm{Y}_{2} \mathrm{O}_{3}$ powders, to analyze their structure and properties and to demonstrate the possibility of making an Al-based MMC using these powders. 


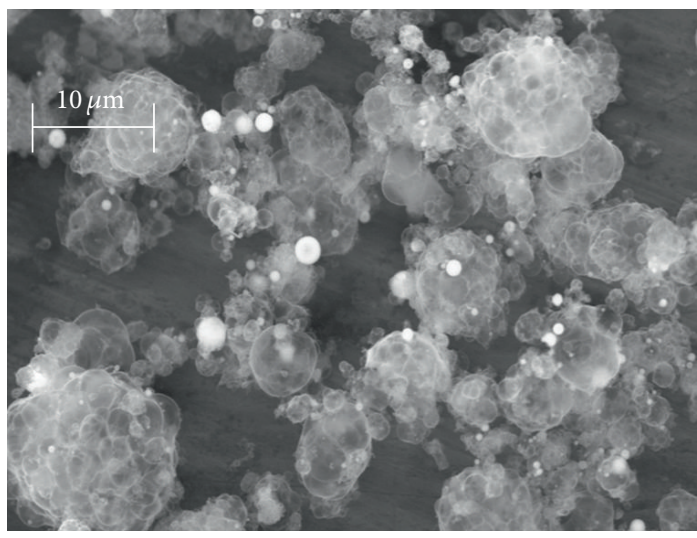

(a)

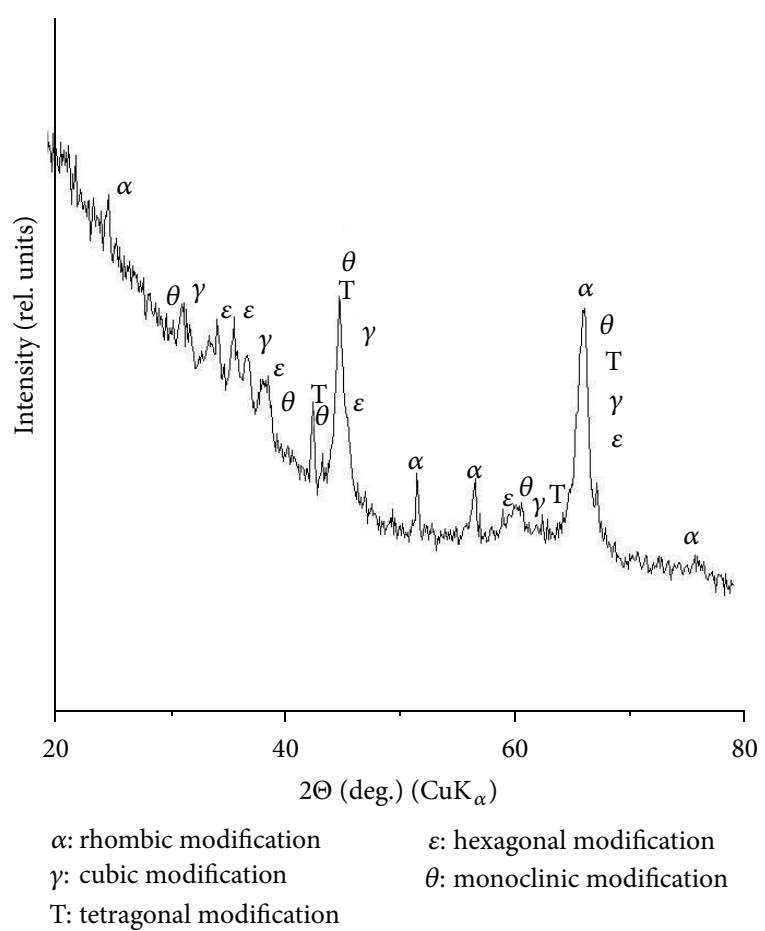

(b)

Figure 1: Powder $\mathrm{Al}_{2} \mathrm{O}_{3}$-plasma: SEM image (a); X-ray pattern (b).

\section{Materials and Methods}

2.1. Production of Nanopowders. Two methods were used for production of micro- and nanoparticles of oxides, that is, plasma-chemical and electrical explosion of wire (EEW).

In plasma-chemical method fine powders were synthesized by means of thermochemical decomposition of liquid sprayed agents in a high-temperature heat transfer medium. The process of synthesis takes place in a columntype direct-flow cylindrical reactor. Water solution of a salt (e.g., aluminum nitrate hydrate $\left.\mathrm{Al}\left(\mathrm{NO}_{3}\right)_{3} \times 9 \mathrm{H}_{2} \mathrm{O}\right)$ is used as an initial agent (precursor). Supply of solution to the reactor chamber is performed via a centrifugal atomizer, providing droplets of sprayed agent with required dispersion. High-frequency plasmatron (with air or argon as a plasma forming gas) is used as a high-temperature heat transfer medium generator. Managing the temperature field structure in the reactor volume is the main control parameter for the evolution of droplet medium and particle morphology.

Nanooxides are also produced using EEW method by means of passing the current pulse with a density of 1$1000 \mathrm{MA} / \mathrm{cm}^{2}$. The metal of the wire heats up to the melting point and melts with subsequent explosive destruction. The process is accompanied by metal atomization and a shockwave formed in the gas surrounding the wire. Depending on the nature of the gas and material of the wire, the EEW process makes it possible to obtain nanopowders of metals, alloys, or compounds. The process parameters which determine average size of nanoparticles are EEW energy content $E / E c$ ( $E$ : energy delivered to the wire, $E c$ : energy of metal sublimation); wire diameter; gas medium pressure; and gas medium temperature. In the developed reactor design, the final product (nanopowder) is evacuated from the chamber by means of gas flows formed as a result of explosion. A special separator is used to screen out coarse particles (having the size greater than $200 \mathrm{~nm}$ ).

2.2. Structural Analysis Methods. The structure of powders was studied using a Philips SEM 515 scanning electron microscope (SEM) and a JEM 2100 transmission electron microscope (TEM). The average size of powder particles was measured using the random linear intercept method [11].

The study of the phase composition and structural parameters of powders was performed using an X-ray diffractometer with $\mathrm{CuK} \alpha$ radiation. Calculation of coherent scattering region (CSR) and microdistortion of the crystal lattice $\left\langle\varepsilon^{2}\right\rangle^{1 / 2}$ was performed using Williamson-Hall method [12] where all broadenings in the X-ray diffraction (XRD) profile were used for calculation. Phases were identified by comparing peaks of X-ray spectra with ASTM (American Society for Testing and Materials) card file. Specific surface area of powders was measured by BET method using a Sorbi analyzer with the measurement error not exceeding 3\%.

2.3. Production of Shock-Wave-Master Alloys and AlComposite Alloys. A possibility of making a shock-wave (SW) concentrated master alloy with nanoparticles and using it in production of nanocomposites was tested on the $\mathrm{Al}$ $\mathrm{Al}_{2} \mathrm{O}_{3}$ system. An $\mathrm{Al}-10 \mathrm{wt} \% \mathrm{Al}_{2} \mathrm{O}_{3}$ (EEW) powder mixture was premixed in a ball mill and then placed into an Al tube with a length of $400 \mathrm{~mm}$ and a diameter of $20 \mathrm{~mm}$. A pure $\mathrm{Al}$ 


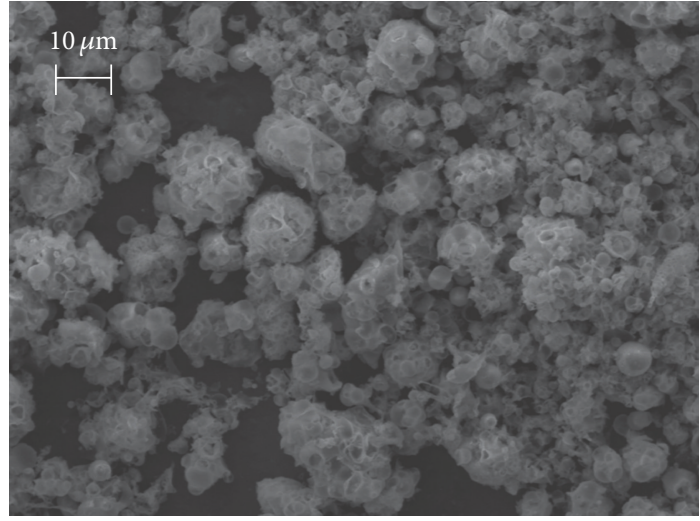

(a)

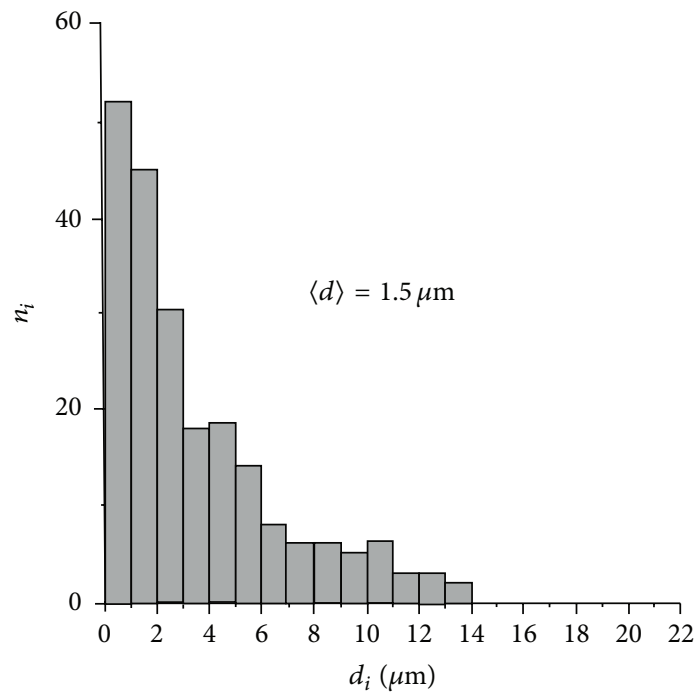

(c)

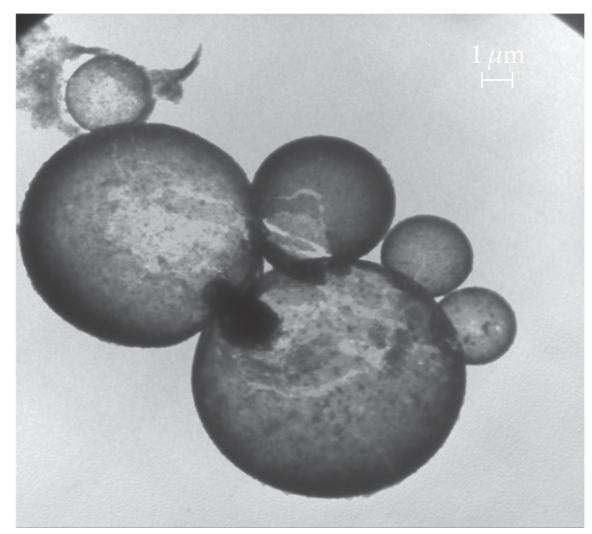

(b)

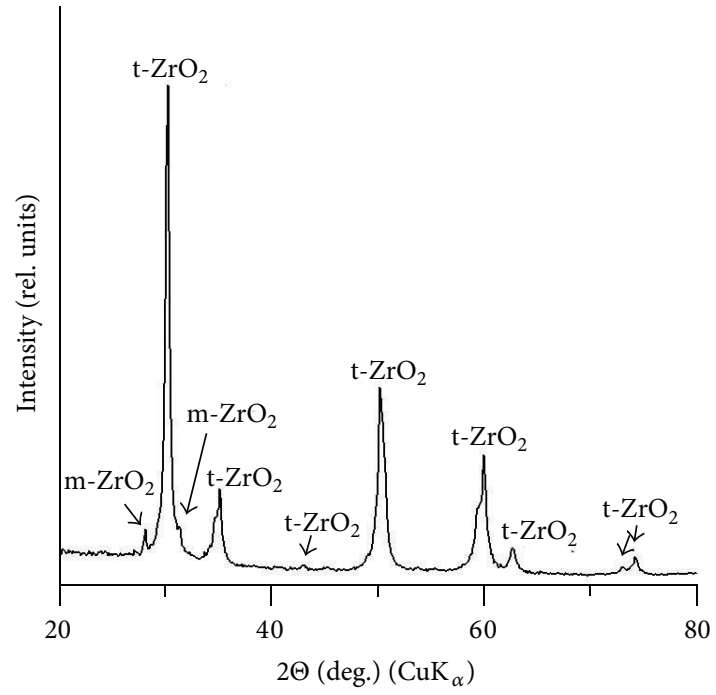

(d)

Figure 2: Powder $\mathrm{ZrO}_{2}\left(\mathrm{Y}_{2} \mathrm{O}_{3}\right)$-plasma: SEM image (a); TEM image (b); particle size distribution (c); X-ray pattern (d).

micropowder with an average particle size of $20 \mu \mathrm{m}$ was used as a matrix material of the master alloy (90\%). A powder mixture with the given composition was densely pressed into $\mathrm{Al}$ tube; both ends of the tube were then hermetically sealed. Compacted explosive was put into the cup $50 \mathrm{~mm}$ above the tube. A standard electric detonator was installed in the middle of this layer at a $20 \mathrm{~mm}$ depth. Total mass of explosive was around $860 \mathrm{~g}$. The assembly was put into the blast chamber on a metal plate, detonator was connected to initiation circuit, the chamber was closed, and the assembly was detonated. The density of the compacted master alloy was $2.6-2.7 \mathrm{~g} / \mathrm{cm}^{3}$, that is, close to the theoretical value for aluminum. More detailed description of this experiment is given in [10].

An aluminum alloy $\mathrm{Al}-4 \mathrm{wt} \% \mathrm{Cu}$ was melted in a graphite crucible with a total melt volume of $750 \mathrm{~g}$. Ultrasonic degassing was performed at the melt temperature of $730^{\circ} \mathrm{C}$ for 1 minute. Then, SW-master alloy Al-10 wt $\% \mathrm{Al}_{2} \mathrm{O}_{3}$ was introduced into the cavitation zone in the melt simultaneously with ultrasonic treatment. The latter was performed using a $5 \mathrm{~kW}$ water-cooled magnetostrictive transducer with a working frequency of $17.5 \mathrm{kHz}$. Conical radiator with a working null-peak amplitude of about $30 \mu \mathrm{m}$ was made of niobium. The melt was treated with ultrasound for 2 minutes at $730^{\circ} \mathrm{C}$ after introduction of the master alloy. Then the obtained mixture was poured at $710^{\circ} \mathrm{C}$ into a metallic mold with the cavity size of $\varnothing 30 \times 110 \mathrm{~mm}$. The nominal nanoparticles content in the alloy was $0.1 \mathrm{wt} \%$. A reference sample was produced using similar processing parameters but without master alloy introduction.

Flat tensile samples with the dimensions of $1 \mathrm{~mm}$ thickness and working part $40 \mathrm{~mm}$ were cut from cylindrical castings and tested in a tensile machine Instron 3369 at a strain rate of $2 \times 10^{-4} \mathrm{~s}^{-1}$. Guaranteed frame stiffness for this machine corresponds to $250 \mathrm{kN}$ load, load accuracy of $0.5 \%$ of indicated load. Ultimate load during specimen testing procedures did not exceed $1.5 \mathrm{kN}$. Three samples were tested for each condition.

\section{Results and Discussion}

3.1. Powders. Nanopowders produced using plasma-chemical method represented a structure formed by individual 


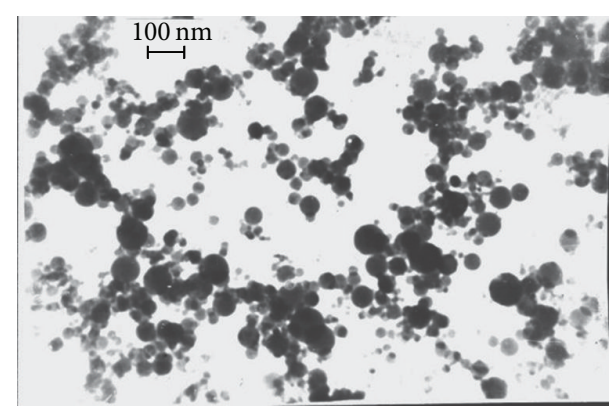

(a)

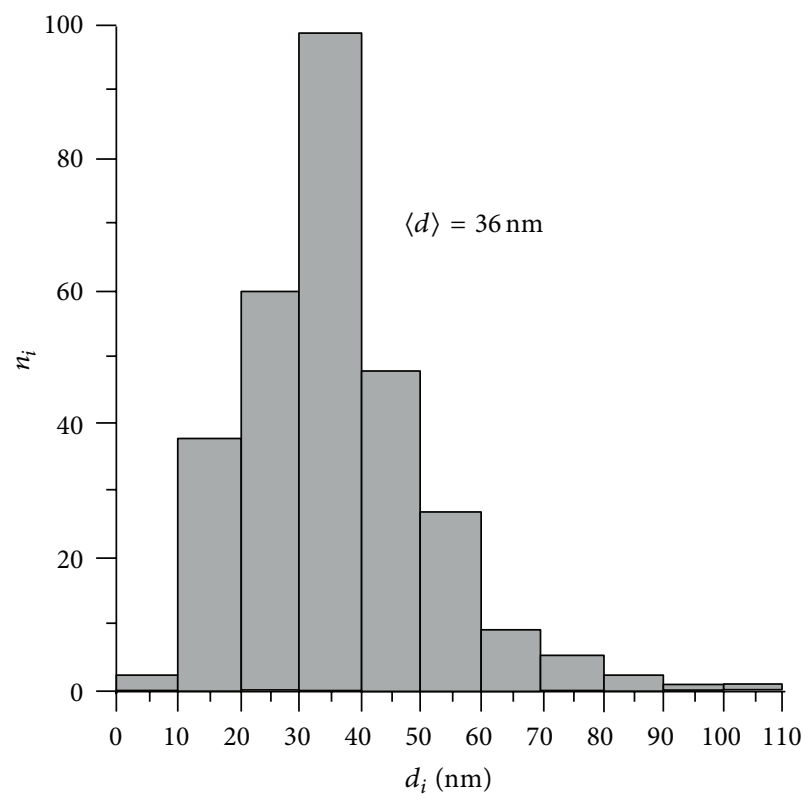

(b)

FIgure 3: Powder $\mathrm{Al}_{2} \mathrm{O}_{3}$-EEW: TEM image (a); particle size distribution (b).

spherical particles and bulk aggregated loose substance consisting of particles having irregular form (Figures 1 and 2).

Alumina powder (Figure 1(a)) has a nonuniform morphology and contains quasi-foam agglomerates with a smooth surface and sizes in the range of tens of nanometers to tens of micrometers. There are also separate spherical particles, hollow particles (wall thickness less than $10 \mathrm{~nm}$ ), and solid fragments. Agglomerates can be divided into the following groups:

(1) quasi-foam particles consisting of semitransparent spherical formations with an internal free volume and a size of $\approx 5 \mu \mathrm{m}$,

(2) solid spherical particles with the sizes of $(0.2-5) \mu \mathrm{m}$,

(3) hollow porous polycrystalline spheres with the size of $1 \mu \mathrm{m}$.

The BET surface of plasma-chemical powder has been measured to amount to $60 \mathrm{~m}^{2} / \mathrm{g}$.

Phase analysis (Figure 1(b)) has indicated that alumina powder is in a highly nonequilibrium state and contains 5 structural modifications: rhombic $(\alpha)$, cubic $(\gamma)$, tetragonal, hexagonal $(\varepsilon)$, and monoclinic $(\theta)$. According to XRD analysis data the size of coherent scattering regions of alumina powder is approximately $30 \mathrm{~nm}$. The crystal lattice microdistortion is $5 \times 10^{-3}$.

$\mathrm{ZrO}_{2}\left(\mathrm{Y}_{2} \mathrm{O}_{3}\right)$ powder was a solid solution of $97 \% \mathrm{ZrO}_{2}-$ $3 \% \mathrm{Y}_{2} \mathrm{O}_{3}$ composition and was obtained by plasma-chemical method. According to electron microscopy (Figures 2(a) and 2(b)), $\mathrm{ZrO}_{2}\left(\mathrm{Y}_{2} \mathrm{O}_{3}\right)$ powder consisted of isolated spherical particles and numerous aggregates composed of particles without regular shape. Particle distribution for $\mathrm{ZrO}_{2}\left(\mathrm{Y}_{2} \mathrm{O}_{3}\right)$ powders is unimodal (Figure 2(c)). The majority of the particles range in size from 0.5 to $2 \mu \mathrm{m}$; some particles have a size of $14 \mu \mathrm{m}$. Average particle size is $1.5 \mu \mathrm{m}$ with the BET surface area being $7 \mathrm{~m}^{2} / \mathrm{g}$.

According to X-ray analysis (Figure 2(d)), the powder contained tetragonal and monoclinic phases of zirconia. The tetragonal phase of zirconia prevailed, its share in the powder being $90 \%$. The size of coherent scattering region of X-rays in tetragonal and monoclinic phases was $20 \mathrm{~nm}$. The crystal lattice microdistortion value was $2.4 \times 10^{-3}$ and the lattice parameters were $c=5.1749 \AA$ and $a=5.1028 \AA$.

The comparison of $\mathrm{ZrO}_{2}$ tetragonal phase lattice parameters with the values given in work [13] showed that the values of lattice parameters for zirconia powder obtained by plasma-chemical synthesis correspond to the values reported for tetragonal phase in the powders composed of $\mathrm{ZrO}_{2}+$ 3 mol. $\% \mathrm{Y}_{2} \mathrm{O}_{3}$.

$\mathrm{X}$-ray phase analysis shows that $\mathrm{Al}_{2} \mathrm{O}_{3}$ powders produced using EEW method completely consist of $\alpha-\mathrm{Al}_{2} \mathrm{O}_{3}$ phase. The BET surface area is equal to $35-40 \mathrm{~m}^{2} / \mathrm{g}$. Typical image of particles of the powder is shown in Figure 3(a). As it can be seen, the particles in the powder are not agglomerated and have a regular spherical shape. Particle size distribution bar chart is shown in Figure 3(b). Average particle size $\widetilde{a}_{n}=$ $36 \mathrm{~nm}$; surface average size $\tilde{a}_{s}=45 \mathrm{~nm}$; mass average size $\tilde{a}_{m}=54 \mathrm{~nm}$. These powders are much more suitable for introduction in a metallic matrix than that for a composite material.

3.2. Al-Based Composite Alloy with $\mathrm{Al}_{2} \mathrm{O}_{3}$ Nanoparticles. $\mathrm{Al}_{2} \mathrm{O}_{3}$-EEW nanoparticles were used as reinforcing particles for introduction into an $\mathrm{Al}$ alloy. Densely compacted master alloy containing $10 \mathrm{wt} \%$ of nanoparticles was introduced into the $\mathrm{Al}$ melt with simultaneous ultrasonic processing. The microstructure of an Al- $4 \mathrm{wt} \% \mathrm{Cu}-0.1 \mathrm{wt} \% \mathrm{Al}_{2} \mathrm{O}_{3}$ alloy is given in Figure 4. As it can be seen, there are $\mathrm{Al}_{2} \mathrm{O}_{3}$ particle agglomerates, evenly distributed spherical particles, and small pores up to $10 \mu \mathrm{m}$ in size in as-cast structure. Note that the grain size and general microstructural appearance of the alloy did not change. The residual porosity of as-cast alloys and composites did not exceed $2 \%$.

The stress-strain tensile curves for produced samples are given in Figure 4(c). As it can be seen, the introduction of $0.1 \% \mathrm{Al}_{2} \mathrm{O}_{3}$ nanoparticles into the alloy leads to simultaneous improvement of yield strength, ultimate tensile strength, and ductility. Moreover, alloy hardness also increases from 570 to $710 \mathrm{MPa}$. The structure of the composite material is still far from being optimal with nanoparticles agglomerates and 


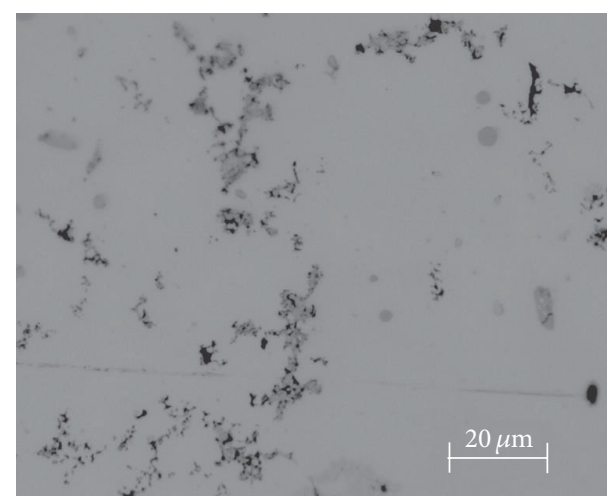

(a)

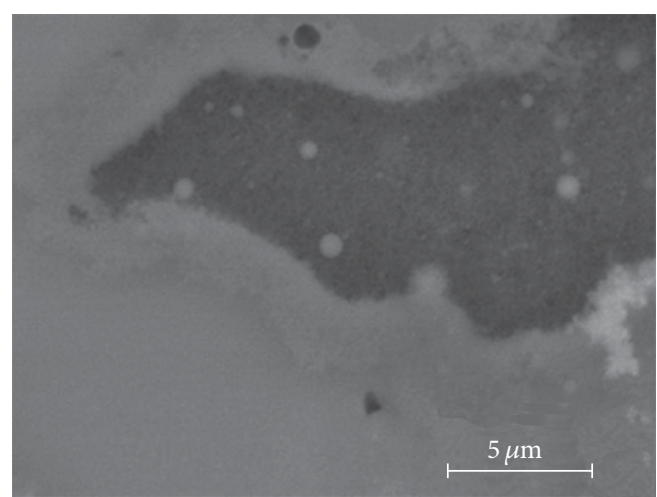

(b)

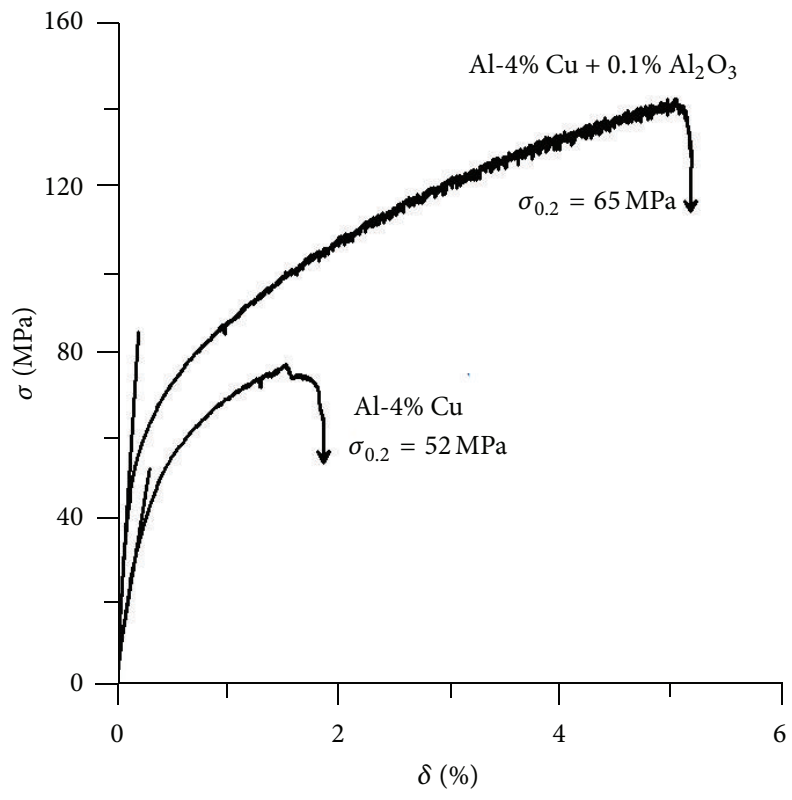

(c)

FIgURE 4: Microstructure of the as-cast composite material Al- $4 \mathrm{wt} \% \mathrm{Cu}+0.1 \mathrm{wt} \% \mathrm{Al}_{2} \mathrm{O}_{3}((\mathrm{a})$, (b)) and stress-strain diagrams of this composite material in comparison with the matrix (c).

associated porosity. The simultaneous increase in strength and ductility can be attributed to a more homogeneous strain distribution upon deformation due to the interaction of dislocations with the particles. The procedure of composite material manufacturing should be further optimized to assure more complete deagglomeration of particles.

\section{Conclusion}

The possibility of production of micro- and nanopowders of metal oxides $\mathrm{Al}_{2} \mathrm{O}_{3}$ and $\mathrm{ZrO}_{2}\left(\mathrm{Y}_{2} \mathrm{O}_{3}\right)$ by electric explosion of wire (EEW) and plasma-chemical methods is shown. Powders produced by plasma-chemical method are characterized with large irregular shapes and severe agglomeration. In contrast, $\mathrm{Al}_{2} \mathrm{O}_{3}$ particles in the powder produced by EEW method are not agglomerated and have regular spherical shape and average size of $36 \mathrm{~nm}$.

It is found that introduction through a concentrated master alloy of $0.1 \mathrm{wt} \% \mathrm{Al}_{2} \mathrm{O}_{3}$ nanoparticles into an $\mathrm{Al}$ alloy leads to improvement of mechanical properties of the resultant MMC.

\section{Conflict of Interests}

The authors declare that there is no conflict of interests regarding the publication of this paper.

\section{Acknowledgments}

The work was financially supported by the Ministry of Education and Science of the Russian Federation within the framework of the Federal Target Program, Agreement no. 14.578.21.0025, and within the framework of ExoMet Project, which is cofunded by the European Commission and partners in the 7th Framework Program (Contract FP7NMP3-LA-2012-280421). 


\section{References}

[1] F. He, Q. Han, and M. J. Jackson, "Nanoparticulate reinforced metal matrix nanocomposites -a review," International Journal of Nanoparticles, vol. 1, no. 4, pp. 301-309, 2008.

[2] W. H. Sillekens, D. J. Jarvis, A. Vorozhtsov et al., "The ExoMet project: EU/ESA research on high-performance light-metal alloys and nanocomposites," Metallurgical and Materials Transactions A, vol. 45, no. 8, pp. 3349-3361, 2014.

[3] M. Sherif and E. Eskandarany, "Mechanical solid state mixing for synthesizing of $\mathrm{SiC} / \mathrm{Al}$ nanocomposites," Journal of Alloys and Compounds, vol. 279, pp. 263-271, 1998.

[4] S. A. Vorozhtsov, S. P. Buyakova, and S. N. Kul'kov, "Synthesis,

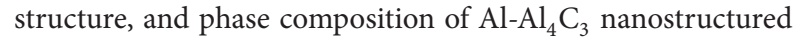
materials," Russian Journal of Non-Ferrous Metals, vol. 53, no. 5, pp. 420-424, 2012.

[5] S. N. Kulkov and S. A. Vorozhtsov, "Structure and mechanical

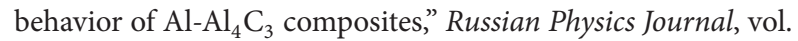
53, no. 11, pp. 1153-1157, 2011.

[6] S. Vorozhtsov, D. Eskin, A. Vorozhtsov, and S. Kulkov, "Physicomechanical and electrical properties of aluminum-based composite materials with carbon nanoparticles," in Light Metals 2014, J. Grandfield, Ed., pp. 1373-1377, TMS (The Minerals, Metals and Materials Society), 2014.

[7] G. I. Eskin and D. G. Eskin, "Production of natural and synthesized aluminum-based composite materials with the aid of ultrasonic (cavitation) treatment of the melt," Ultrasonics Sonochemistry, vol. 10, no. 4-5, pp. 297-301, 2003.

[8] H. Choi, M. Jones, H. Konishi, and X. Li, "Effect of combined addition of $\mathrm{Cu}$ and aluminum oxide nanoparticles on mechanical properties and microstructure of Al-7Si-0.3Mg alloy," Metallurgical and Materials Transactions A: Physical Metallurgy and Materials Science, vol. 43, no. 2, pp. 738-746, 2012.

[9] S. N. Kulkov, S. A. Vorozhtsov, V. F. Komarov, and V. V. Promakhov, "Structure, phase composition, and mechanical properties of aluminum alloys produced by shock-wave compaction," Russian Physics Journal, vol. 56, no. 1, pp. 85-89, 2013.

[10] S. Vorozhtsov, A. Vorozhtsov, S. Kulkov, and V. Komarov, “The physical-mechanical properties of aluminum nanocomposites produced by high energy explosion impact," in Light Metals, J. Grandfield, Ed., pp. 1397-1400, TMS (The Minerals, Metals and Materials Society), 2014.

[11] A. M. Gokhale, "Quantitative characterization and representation of global microstructural geometry," in ASM Handbook, Vol. 9, Metallography and Microstructures, pp. 428-447, ASM International, Metals Park, Ohio, USA, 2004.

[12] G. K. Williamson and W. H. Hall, "X-ray line broadening from filed aluminium and wolfram," Acta Metallurgica, vol. 1, no. 1, pp. 22-31, 1953.

[13] R. P. Ingel and D. Lewis III, "Lattice parameters and density for $\mathrm{Y}_{2} \mathrm{O}_{3}$-stabilized $\mathrm{ZrO}_{2}$," Journal of the American Ceramic Society, vol. 69, no. 4, pp. 325-332, 1986. 

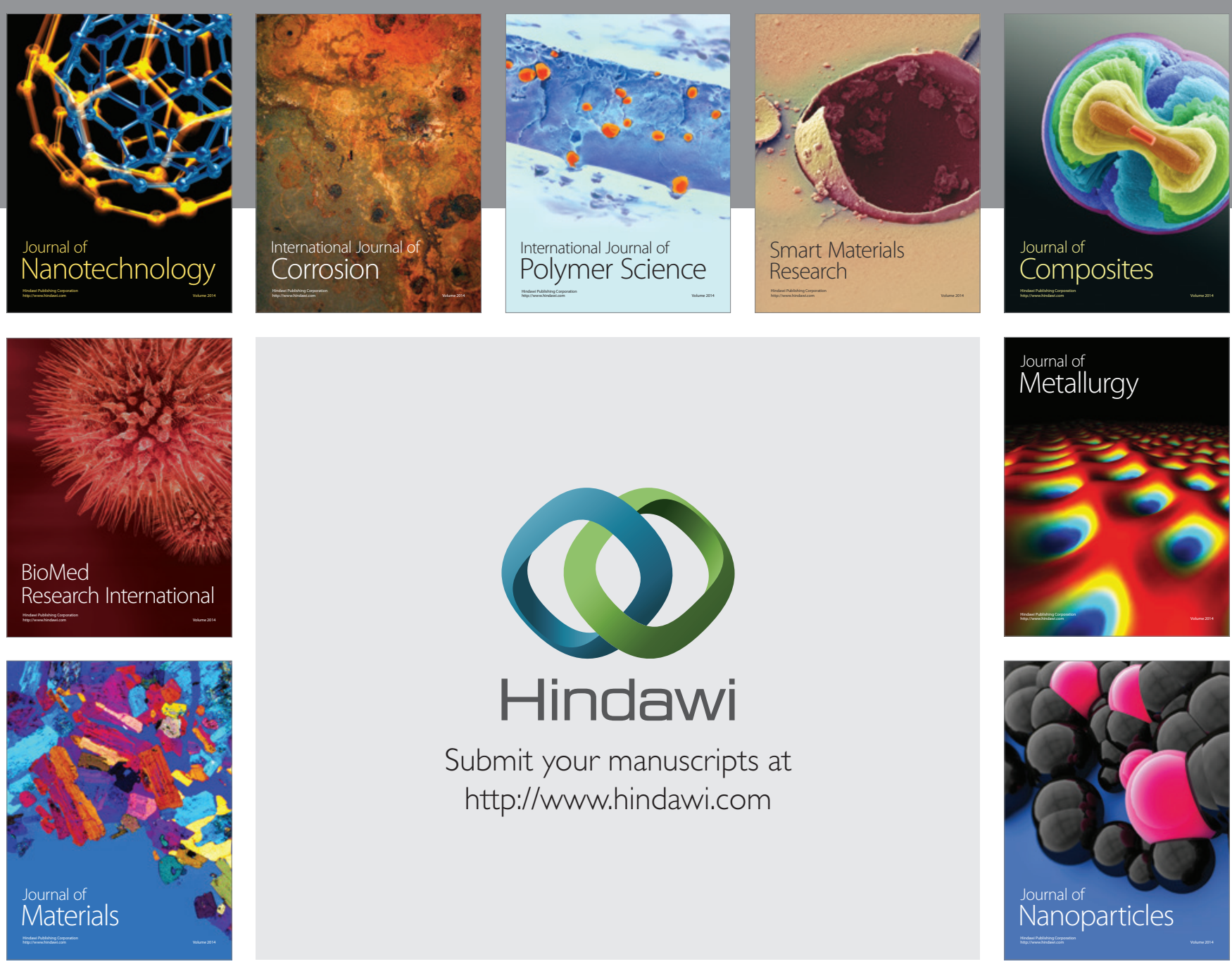

Submit your manuscripts at http://www.hindawi.com
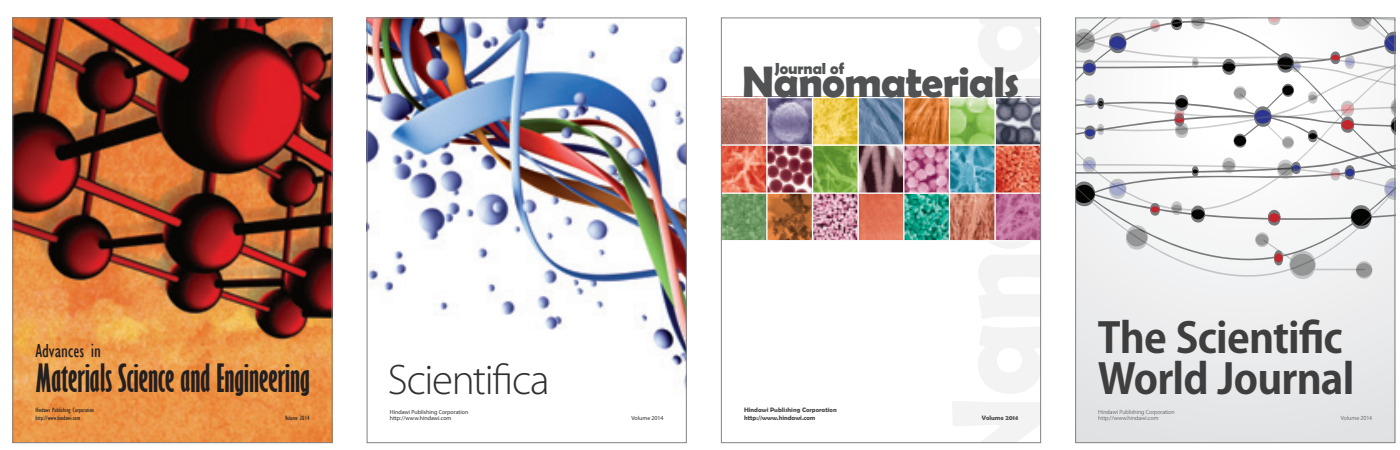

\section{The Scientific World Journal}
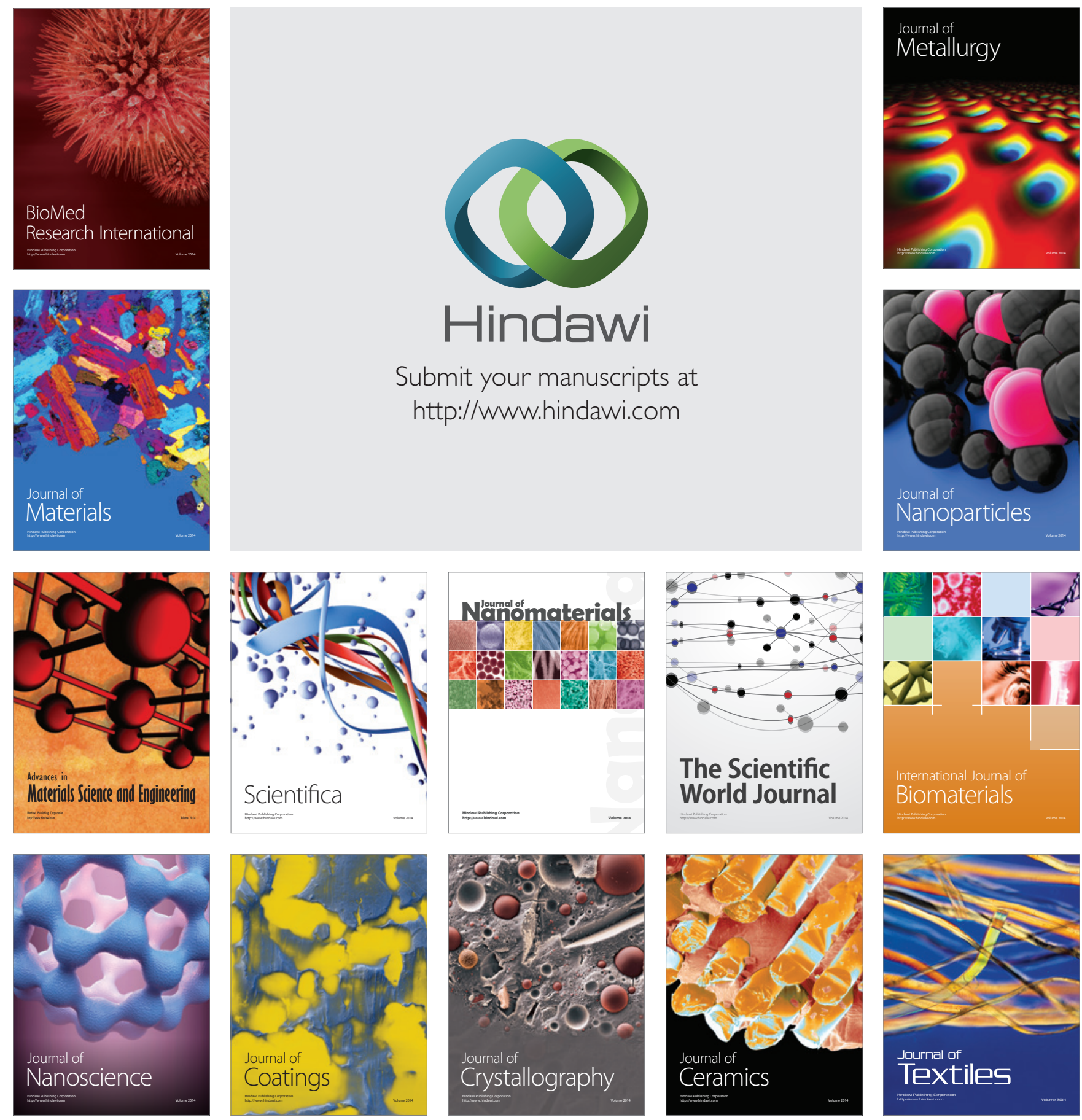